\title{
Application of BIM technologies in construction in Russia
}

\author{
Tatiana Kisel $^{1, *}$ \\ ${ }^{1}$ Moscow State University of Civil Engineering, 129337, 26, Yaroslavskoye Shosse, Moscow, Russia
}

\begin{abstract}
The objective of the research is to define the level of the use of BIM technologies (Building Information Modeling, or information modeling of buildings and structures) by the Russian companies. The identification of the reasons of BIM introduction or its refusal was also carried out. The advantages given by the use of BIM were revealed. It was proved that the BIM technologies promote the reduction of terms of the project implementation, the general upgrading of the project documentation and the construction-and-installation works performed on its basis, as well as the reduction of the project cost. The results of the research proved that $22 \%$ of the Russian enterprises of the investment-andstructural sphere use BIM during various stages of introduction. The application of BIM allows getting some advantages, including the improved understanding of the project by all the participants, high quality of the project, availability of information, fast data transmission and exchange of information, reduction of terms of design and/or construction. The results of the research can be useful for the numerous participants of the investment-and-structural sphere, who have individual, sometimes contradictory interests.
\end{abstract}

\section{Introduction}

Modern construction is the sphere of high technologies and innovations because of the extraordinary information saturation and technology complexity. The need of collecting, accounting, processing and the subsequent adjustment of considerable information massifs during the design, construction and maintenance of the capital construction projects resulted in the need to use the modern information technologies and some specialized software products. Such products are known to be directed on the creation of the digital information model of a construction project. The process of the creation and information management during all the stages of the construction project lifecycle in its information (program) environment was named Building Information Modeling (BIM). Nowadays, a rather high level of the use of BIM technologies is noted in the USA [1-2], some developed countries of Europe [3-6] and Asia [7-9]. Numerous examples of the projects, implemented with the use of BIM, prove that this technology promotes the reduction of project deadlines, the general improvement of quality of the project documentation and the construction-andinstallation works, performed on its basis as well as the reduction in the project cost [10-

* Corresponding author: doremi2@yandex.ru, angela-1309.m@yandex.ru 
11]. It should be noted that the high level of the use of BIM technologies is observed, first of all in the countries, where their development is kept by the state, acting both as the regulator and as the customer of works. For example, the use of BIM technologies is obligatory, when constructing facilities according to the state order in Great Britain and Singapore.

The development of BIM technologies in Russia got support in 2014, when the Plan of stage-by-stage implementation of the technologies of information modeling in the field of industrial and civil engineering was approved [12].

The plan of the Ministry of Construction, Housing and Utilities of the Russian Federation is to transfer the whole state order at all the levels of the budgetary system of the Russian Federation to BIM technologies within the next 3...5 years. However, there was no information about the level of implementation of BIM technologies at the Russian enterprises of the investment-and-construction sphere. In the western countries, some research for the identification of the level of the use of BIM results (economic efficiency) are carried out regularly [13-16]. But in Russia, such research was carried out for the first time. The determination of the level of the use of technologies of information modeling by the Russian companies became the research purpose. It is also possible to point out such accompanying purposes as the identification of the reasons of the introduction or the reasons of refusal of BIM, as well as the advantages, provided by the use of BIM.

Nowadays, the analysis of the general level of introduction of BIM at the Russian enterprises of the construction sector has the high importance. It will allow determining the capacity of the industry after transition of the total state order to BIM technologies. It will also allow defining some supporting and corrective actions, which in turn will allow performing this transition to the specified time frames.

\section{Materials and Methods}

The research was divided into 2 blocks for the better achievement of its purposes.

1. Telephone survey.

The possibility of spontaneous selection of participants with the criterion of the relevance to the investment-and-construction sphere and the brevity of the poll allowed providing the selection representativeness. The enterprises and the organizations of the investment-and-construction sphere were chosen from the databases which are in the open access. The proper selection size was provided during the telephone survey. That allowed speaking about the low probability of a mistake and, respectively, about the high quality of the results. Thus, the telephone survey fulfilled the function of a classical quantitative research. Such a quantitative research, allows judging how many organizations of the investment-and-construction sphere (with the shift for the benefit of the project organizations) introduced and use technologies of information modeling in their work. It is necessary to make the clause for ensuring the reliability of the provided results, as various people and various organizations understood BIM differently. Therefore, both experienced and confident users, and the organizations using only some BIM elements could enter the group of those, who use BIM. However, that does not reduce the value of the received results. That just proves more likely that the organizations, announcing their work with BIM (even in case if they use only some of its elements), seek to develop in this direction and to identify themselves with the users of BIM.

Thanks to the volume and quality of selection, the telephone survey allows drawing some conclusions on the level of the use of technologies of information modeling in the practice of the modern Russian enterprises of the investment-and-construction sphere. The shift to the enterprises, which are the main users of BIM, i.e. to the design organizations, takes place. 
The method of selective indirect survey was applied for the determination of the average level of the use of BIM technologies in Russia. The survey was carried out in the form of the telephone questioning with the representatives of the enterprises of the investment-and-construction sphere. A short questionnaire was used. The enterprises of the investment-and-construction sphere of various functional orientation acted as the target audience (including investors, developers, technical customers, general contractors, designers, etc.). The application of this method has some disadvantages, connected with the competence answering and with the little quantity of questions. However, it allows drawing some conclusions on the level of the use of BIM at all the enterprises of the investmentand-construction sphere. That is possible as the method provides the selection with the necessary level of representativeness in relation to the population. The feature of the application of this method is the vigilance of the respondents, their unwillingness to answer the questions about the social-and-demographic data of the respondents (in particular, to call their names or the name of the organization).

A short questionnaire was used as the tool of the survey. The brevity of the questionnaire is the important requirement, when carrying out telephone surveys, as it allows keeping attention of the respondent and does not take much time. That makes the participation in the survey comfortable for the respondents. Besides, the brevity is also connected with the perception of information on phone, which also has some features and restrictions.

2. Online questioning.

The identification of the main obstacles to the development of technologies of information modeling, compliance of expectations from the introduction of BIM to the received results and also plans for the introduction or reasons for refusal of introduction of BIM became its purpose. This research should be considered to be qualitative and quantitative, as its main objectives were in the area of studying of the quality characteristics of the respondents, both from the group of those, who use BIM, and from the group of the organizations, which do not use BIM. The results of the online questioning allow concentrating the attention not only on the strengths of the technologies of information modeling, but also on the main obstacles of its development in order to plan some necessary actions and to predict the rates of transition of the organizations of the industry to the technologies of information modeling as the main method of the projects implementation.

The research was carried out by the means of the method of selective indirect survey in the form of online questioning. The advantage of online questioning is the absence of influence of a questionnaire on the respondent's opinion during the survey; that allows receiving the "purest" result. The target audience were the enterprises of the investmentand-construction sphere. At the same time the participation in the survey was absolutely voluntary. The representatives of the enterprises, motivated to express their opinion and thus, taking rather active position on the use of BIM technologies, became the respondents. Such method of data collection allows reducing the quantity of "not productive" and "neutral" answers. It allowed receiving the qualitative result during the research, i.e. revealing not only the quantitative ratios in the selection, but also to define the interrelation reasons. The information about carrying out the survey was distributed throught various channels, including the professional websites, internet mass-media and portals, social networks, websites of the commercial organizations and public authorities as well as conferences, forums, round tables, etc. That was done in order to ensure the participation of the maximum number of the interested and active participants in the questioning. Such approach to forming of selection provided the competence of the survey participants; respondents were informed on what is technologies of information modelling, and they were competent to express an informed opinion on the matter. 
The online questionnaire consisting of several blocks acted the tool of the survey:

1) the block including questions about the name and the type of activity of the organization as well as its size and work experience (questions about the number of employees and the number of the implemented projects) and also the region of location;

2) the block including the questions concerning the respondents' opinion about the use of technologies of information modeling. Questions of this block suppose the differentiation for 2 groups of respondents:

- the respondents who gave positive answers about the use of the technologies of information modeling. They answer the questions about the experience of application of BIM, the software used, the reasons of introduction and the main obstacles to introduction of BIM, etc.;

- the respondents who gave negative answers about the use of technologies of information modeling. They answer the questions about the reasons for refusal of BIM, the availability of plans for introduction and also their attitude to the BIM development.

\section{Results}

\subsection{Results of the telephone survey}

As it was noted, the method of selective indirect survey in the form of a short telephone questioning was used as the method.

Selective surveys suppose the distinction of a certain selection from the general population. In this case, the enterprises and the organizations of the investment-andconstruction sphere were chosen from the databases, which are in open access, as the representatives of the population. The organisations' contacts (phone numbers for carrying out call-down) were found on their official sites or information websites. The selection was 427 organizations. There were organizations of the investment-and-construction sphere of different types of activity among the respondents; they were selected randomly from the open information sources.

The technology of the survey included:

- a call-down according to the openly provided contact information of the organization,

- a short message about the purpose of the call and research purpose,

- an attempt to contact the competent specialist and in case of impossibility to contact the chief engineer/director/designer, etc. (i.e. those who are considered to be the group of competent),

- an attempt to ask a question about the use of technologies of information modeling to the main contact person.

Thus, the following distribution of answers was received for the main question of the research on the use of BIM technologies by the organization in their activity (Figure 1). 


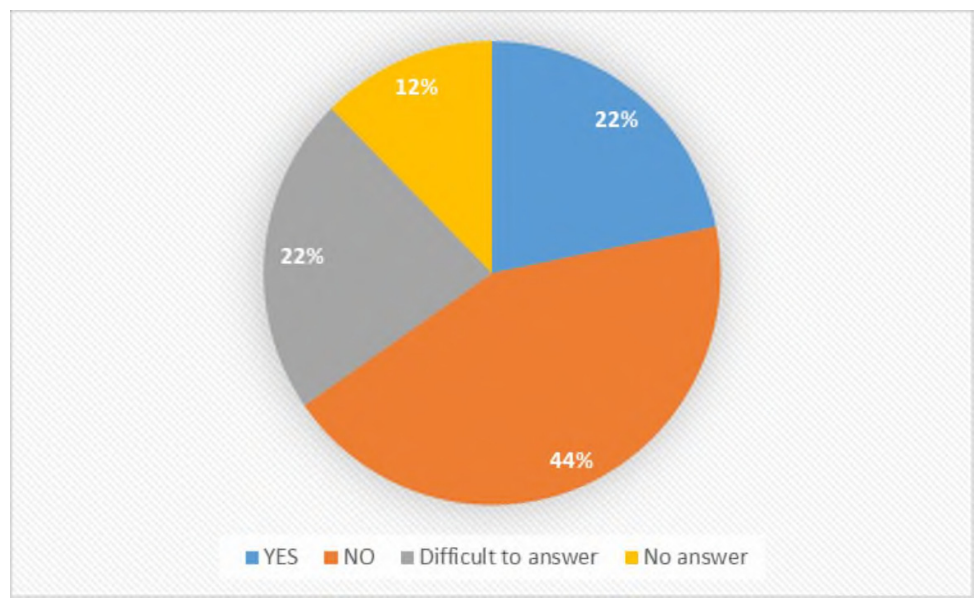

Fig. 1. Results for the question "Does Your Organization Use BIM Technologies for the Work?"

$22 \%$ of the respondents answered that they apply BIM technologies. During specifying the question, different extent of the introduction and various experience (from work on several projects to systematic work for many years) was revealed.

$44 \%$ of the respondents answered that they do not apply BIM technology.

$22 \%$ of the respondents found it difficult to give an exact answer. There was a probability that there were organizations, using technologies of information modeling in a varying degree, among them.

Several respondents among those who were not applying BIM technology noted that they had no orders with the requirement of performance of works in the information model, having an opportunity to work in BIM (availability of specialists and software). They also noted the insufficient demand from investors and customers.

The respondents who gave negative answers for the question of the use of BIM were asked additional questions about the reasons for refusal of introduction and about the plans for the soon introduction. The survey results are presented in Table 1.

Table 1. Reasons for refusal of introduction of BIM and plans for introduction (those, who said that they do not use BIM, were asked the question)

\begin{tabular}{|l|c|}
\hline \multicolumn{1}{|c|}{ Answer } & \multicolumn{1}{|c|}{$\begin{array}{c}\text { Share of the } \\
\text { respondents }\end{array}$} \\
\hline There is bad experience of introduction & $2 \%$ \\
\hline $\begin{array}{l}\text { Subcontract is used, if it is necessary to work with the } \\
\text { application of BIM }\end{array}$ & $1 \%$ \\
\hline There are no orders with the need to use BIM & $1 \%$ \\
\hline $\begin{array}{l}\text { There are some prerequisites for BIM introduction (software, } \\
\text { specialists) }\end{array}$ & $3 \%$ \\
\hline Introduction is intended & $14 \%$ \\
\hline There are no financial resources for the introduction & $2 \%$ \\
\hline That is not considered to be effective & $3 \%$ \\
\hline
\end{tabular}

It should be noted that the survey results proved rather high potential of the development of BIM in the next years. For example, $14 \%$ of the respondents announced their plans of the implementation of BIM technologies in the next $1 . . .3$ years, $3 \%$ of the respondents had a reserve for the introduction (the specialists, already trained or being trained, the purchased software and even some experience of three-dimensional design (creation of a $3 \mathrm{D}$ model). Thus, about $20 \%$ of the respondents who were not using BIM 
technology form the potential of the development of technologies, had desire and/or opportunities to do that soon.

Besides, about $19 \%$ of the respondents declared their interest in BIM technologies. There are respondents, who are interested in the experience of introduction in other organizations, in the results of introduction - cost efficiency, etc. Some respondents who are not informed on the matter were also identified. However, during the call-down they became interested in obtaining more information and even in training; demonstrated the considerable interest and expressed desire.

An attempt to define the structure of the enterprises, using BIM technologies was made during the research. So, $20 \%$ of the enterprises, which reported that the main type of their activity was design, applied BIM technologies. At the same time, 39\% of the revealed enterprises, which applied BIM (93 enterprises, or $22 \%$ ), are the design organizations. That proved the unconditional overweight in the possession of competences of information modeling.

\subsection{Results of the online questioning}

The purpose of the online questioning was the studying of the attitude of the target audience to the use of BIM technologies: the identification of the main obstacles to the development of technologies of information modeling, the compliance of expectations from the introduction of BIM to the received results and also plans for the introduction or reasons for refusal of the introduction of BIM. So, the attitude to the use of BIM technologies, was studied both in the group of the organizations, which used technologies of information modeling, and in the group of the organizations, which did not use them.

As the online questioning is the type of selective survey, it is necessary to characterize the created selection which represents the main characteristics of the population of the enterprises of the investment-and-construction sphere. The enterprises and the organizations of the investment-and-construction sphere, taking an active position, as well as the persons interested to express the opinion concerning the use of BIM technologies, were chosen as the representatives of the population. The selection is created spontaneously. The participation in the survey demanded an initiative, first of all from the respondent and that provided its high quality, competence and availability of the created opinion as well as the interest in the survey topic. The volume of selection, made within the research, was 190 organizations of different types of activity.

$58 \%$ of the respondents named design as their main activity, 34\% named architectural design, $27 \%$ were the enterprises, which perform a complex of works (including the organizations of a complete sales cycle of the investment-and-construction project). Among the respondents, there were also the representatives of the educational organizations, general contractors and technical customers, developers, builders, etc.

The overweight among the respondents towards designers is caused by the fact that project organizations are the first to use the technologies of information modeling. The fact that they are the most competent and interested participants of questioning is also explained by that.

The experience of the survey participants in the investment-and-construction sphere was measured by the total number of the projects, implemented by the organization (Figure 2). 


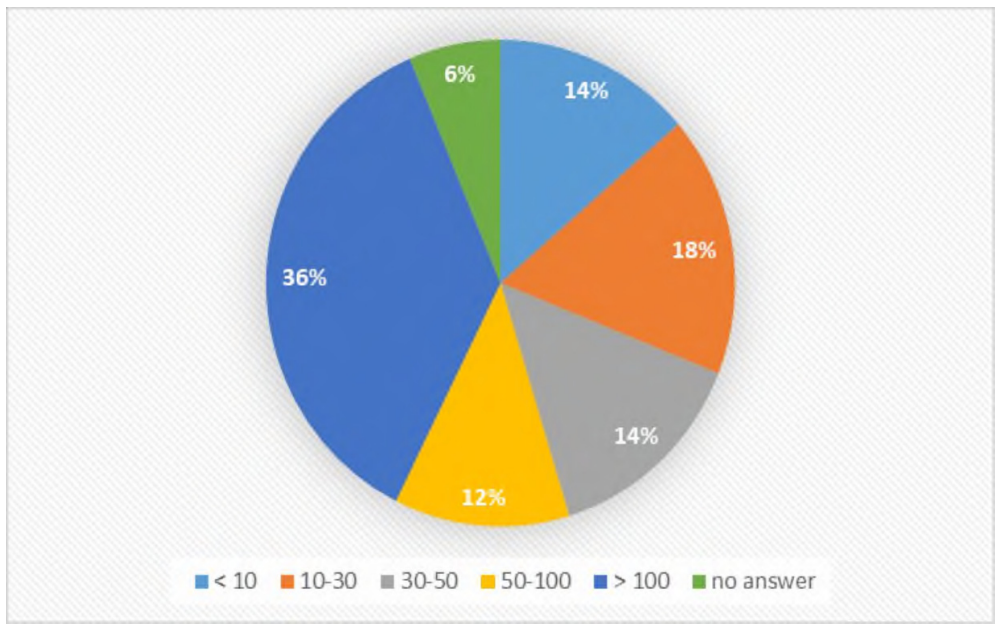

Fig. 2. Experience of the survey participants, expressed in the number of the projects implemented

According to the provided data, we can prove that about a half of the survey participants $(48 \%)$ are the experienced players of the investment-and-construction sphere; they have carried out more than 50 projects. However, considerable interest in the survey was demonstrated by "beginners", i.e. by the organizations, which have carried out less than 10 projects. Despite the brief experience of such new players, they often are more flexible to the introduction of innovations and more opened to any changes.

As for the question whether the organizations (the survey participants) used the technology of information modeling in their work on projects, the answers were distributed as follows (Figure 3).

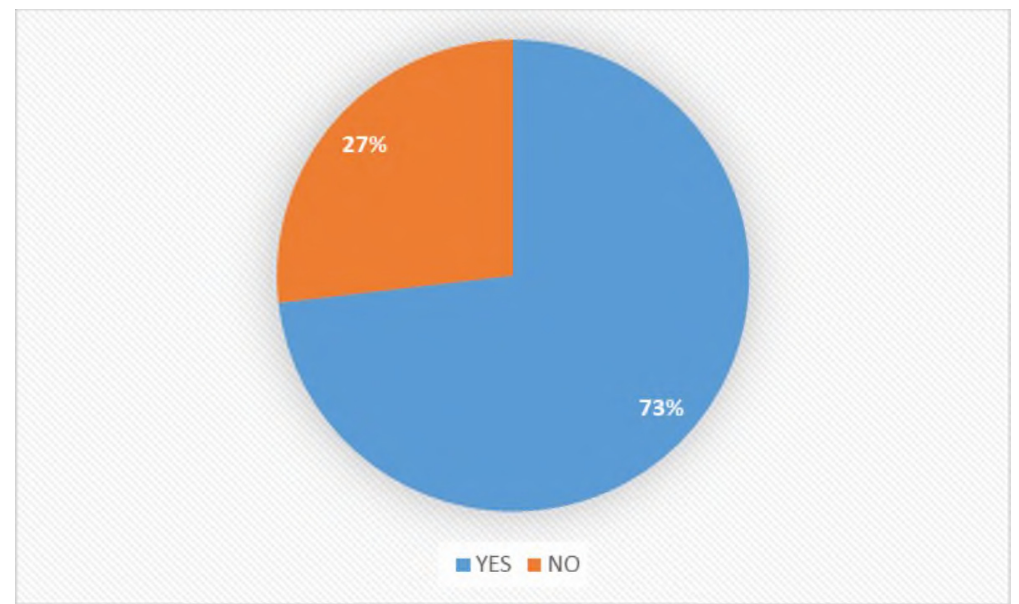

Fig. 3. Quantity of users of technologies of information modeling in the total selection

$73 \%$ of the respondents use technologies of information modeling in their practice, $27 \%$ do not use. Such proportion do not characterize the population and it is proved that this this group of the respondents was interested in the research, and they had the maximum motivation to participate in the survey.

There are both experienced users (17\% of the respondents implemented more than 30 projects on the basis of BIM) and new users (38\% of the respondents implemented no more 
than 5 projects on the basis of BIM) among the respondents using technologies of information modeling during the project implementation.

The determination of the term of the use of appropriate technologies became one more method to assess the work experience of the survey participants in BIM. It is revealed that $31 \%$ of the respondents use BIM in their practice for more than 5 years, $17 \%$ use BIM from 3 to 5 years, $31 \%$ use BIM from 1 to 3 years and $21 \%$ use BIM for less than 1 year.

It was revealed that technologies of information modeling are used during the implementation of the projects of apartment blocks construction most often (44\% of the respondents used BIM for the projects of this type), as well as for the projects of buildings and structures for production appointment $(30 \%)$, and also for the projects of social-andcultural facilities $(26 \%)$ (Table 2).

Table 2. Types of projects, implemented by the respondents with the use of BIM technologies

\begin{tabular}{|l|c|c|}
\hline \multicolumn{1}{|c|}{ Types of projects } & $\begin{array}{c}\text { Quantity of the } \\
\text { respondents' } \\
\text { answers }\end{array}$ & $\begin{array}{c}\text { Share of the } \\
\text { selection }\end{array}$ \\
\hline individual residential houses & 20 & $14 \%$ \\
\hline buildings, structures of production appointment & 42 & $30 \%$ \\
\hline apartment houses & 61 & $44 \%$ \\
\hline social-and-cultural facilities & 36 & $26 \%$ \\
\hline residential city blocks & 25 & $18 \%$ \\
\hline office buildings & 24 & $17 \%$ \\
\hline road construction & 7 & $5 \%$ \\
\hline other facilities & 27 & $19 \%$ \\
\hline
\end{tabular}

The question about the reasons, which pushed the organizations to the implementation of technologies of information modeling, became one of the key questions of this research. Almost identical quantity of the respondents named the increase in the production efficiency, the improvement of quality of works and the search of ways of improving competitiveness as the reasons for introduction of BIM (50\%, 49\% and $46 \%$, respectively) (Table 3).

Table 3. Basic reasons for the introduction of BIM in the respondent organizations

\begin{tabular}{|l|c|c|}
\hline \multicolumn{1}{|c|}{ Reasons for the introduction of BIM } & $\begin{array}{c}\text { Quantity of the } \\
\text { respondents' } \\
\text { answers }\end{array}$ & $\begin{array}{c}\text { Share of the } \\
\text { selection }\end{array}$ \\
\hline improvement of the works quality & 68 & $49 \%$ \\
\hline requirement of customers & 31 & $22 \%$ \\
\hline search of the ways of improving competitiveness & 64 & $56 \%$ \\
\hline $\begin{array}{l}\text { increase in the production efficiency (including the } \\
\text { reduction in cost and terms of works, the increase in } \\
\text { economic return and profitability) }\end{array}$ & 70 & $50 \%$ \\
\hline other reasons & 6 & $4 \%$ \\
\hline
\end{tabular}

Besides, $22 \%$ of the respondents answered that the transition to BIM is connected with the requirements of the customers. The speed of application of repeated decisions, the process automation, convenience and presentation during the project creation, etc. were named among other reasons. 
The initiative of the implementation of technologies of information modeling belongs to the owners of the enterprises most often and that is not surprising. The owner benefits most of all from the general increase in the efficiency of the organization activity and he or she is interested in its development for the long-term prospect. In 18\% of cases, top managers act as initiators, in $19 \%$ of cases, production divisions are noted directly (including and even first of all, designers). In $25 \%$ cases, the initiative belongs to several parties simultaneously.

Further the respondents using BIM for the project implementation were offered to define the main benefits of the use of technologies of information modeling. The distribution of their answers is presented in Table 4.

Table 4. Main advantages which the use of BIM gives to the respondent organizations

\begin{tabular}{|l|c|c|}
\hline \multicolumn{1}{|c|}{ Main advantages of BIM } & $\begin{array}{c}\text { Quantity of the } \\
\text { respondents' answers }\end{array}$ & $\begin{array}{c}\text { Share of the } \\
\text { selection }\end{array}$ \\
\hline increase in profit and profitability & 26 & $19 \%$ \\
\hline cost reduction & 46 & $33 \%$ \\
\hline reduction of terms of design and/or construction & 81 & $58 \%$ \\
\hline high quality of the project & 98 & $71 \%$ \\
\hline 3D and 4D visualization of the building site & 52 & $37 \%$ \\
\hline more effective expenditure of resources & 34 & $24 \%$ \\
\hline $\begin{array}{l}\text { improved understanding of the project by all the } \\
\text { participants }\end{array}$ & 107 & $77 \%$ \\
\hline $\begin{array}{l}\text { availability of information, fast data transmission } \\
\text { and information exchange }\end{array}$ & 93 & $67 \%$ \\
\hline
\end{tabular}

The leading advantages noted by the vast majority of the respondents of were:

- the improved understanding of the project by all the participants $-77 \%$;

- high quality of the project $-71 \%$;

- the availability of information, fast data transmission and information exchange - $67 \%$;

- the reduction of terms of design and/or construction - 58\%.

Answering this question, the respondents, as a rule, noted several advantages simultaneously, which proves high effectiveness of the use of BIM and various manifestations of the gained effect.

Comparison of expectations from the implementation of technologies of information modeling and the received result became one more important item of the questionnaire. It is, perhaps, the main aspect characterizing (though without quite concrete and exact figures) the results of the introduction and efficiency of the use of BIM. The respondents were offered to estimate their expectations from the introduction of BIM and the real effect according to the scale from 1 to 10 , where 1 means that the real effect completely did not meet the expectations and did not justify them, 5 - the received effect completely corresponds to the expectations, which were assigned to the BIM introduction, 10 - the real received effect repeatedly exceeded the initial expectations. Figure 4 provides the distribution of the answers. 


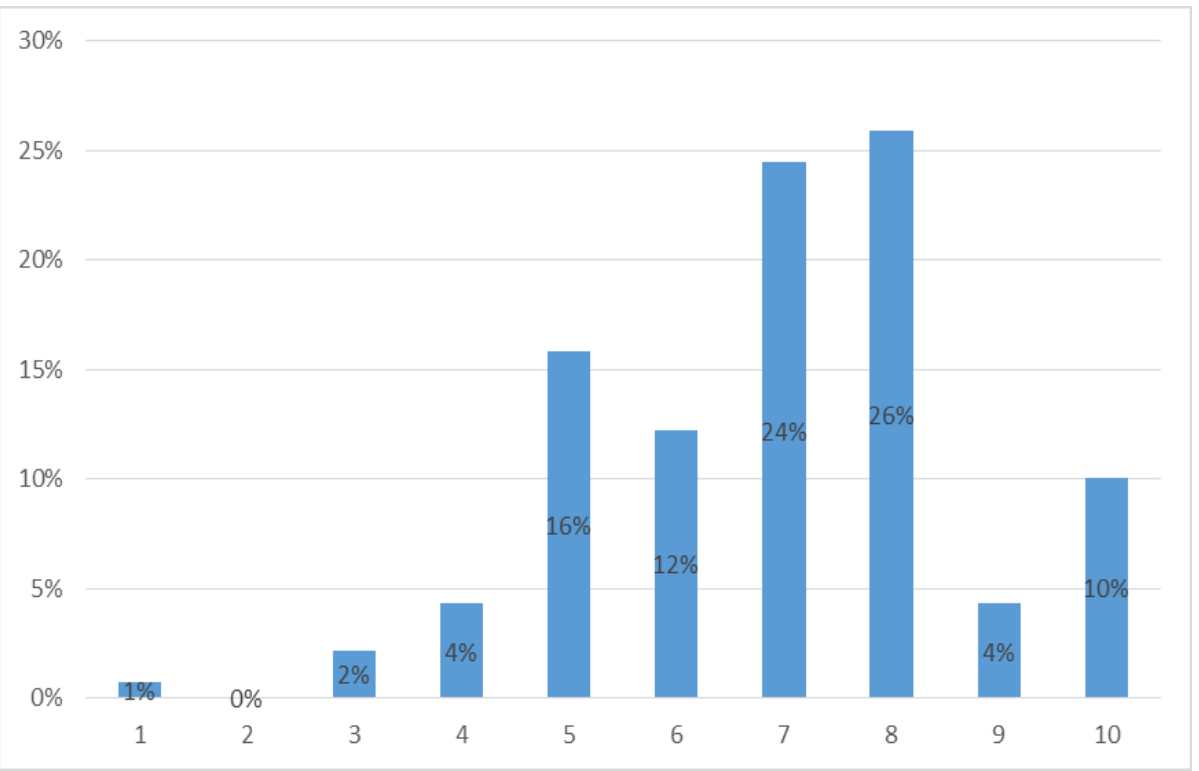

Fig. 4. Results of comparison by the respondents of their expectations from the introduction of BIM and the real received effect according to the scale from 1 to 10

It should be noted that the real received effect of the introduction of BIM exceeded the expectations of $77 \%$ of respondents. At the same time, $10 \%$ of the respondents mentioned that the real effect exceeded their expectations repeatedly. $16 \%$ of the respondents spoke about the full compliance between their expectations and the received effect. Only $7 \%$ of the respondents noted that their expectations were higher, than the real received effect. At the same time the lowest marks (1...3 points) were given by the organizations, having work experience in BIM from 1...3 years and no more than 10 projects carried out with the use of BIM. The increase in work experience in BIM, perhaps, will allow those respondents to gain more considerable effect and to appreciate the use of technologies of information modeling better.

The question about the reasons for the refusal of the implementation of BIM technology became the key question for the group of the respondents who are not using BIM. (We should remind that it makes up $27 \%$ of the survey participants.) $53 \%$ of the respondents noted the absence of the competent employees capable to work in BIM in the organization as such a reason (some respondents also noted the lack of opportunities to train the staff because of the lack of time or the need of separation from work). $43 \%$ of the respondents noted high implementation cost. There were also respondents, who considered the work of the organization to be effective enough without the use of technologies of information modeling (37\% among this group of the respondents).

Some disadvantages of the software products, which are, as a rule, used as the BIM platform, as well as misunderstanding by the owners/managers and their commitment to the traditional design methods of design and management of investment-and-construction projects were noted among other purposes.

At the same time, $32 \%$ of the respondents of this group intend the implementation of BIM technologies in the long term. $10 \%$ of them have plans for the next year, $18 \%$ for the $2 . . .3$ years, $6 \%$ for the $3 . .5$ years. $43 \%$ of the respondents of this group do not intend the introduction of BIM in the next 3...5 years.

The group of the respondents who were not using technology of information modeling was also asked the question about the internal or external motives, which had led the 
organization to the BIM introduction. The distribution of the answers is presented in Table 5.

Table 5. Reasons, which can lead the respondent organization to the implementation of BIM technologies

\begin{tabular}{|l|c|}
\hline \multicolumn{1}{|c|}{ Possible motives of the introduction of BIM } & Share of the selection \\
\hline $\begin{array}{l}\text { Requirements and readiness of the customer, including obligation, } \\
\text { when obtaining the state order }\end{array}$ & $31 \%$ \\
\hline Improvement of the software & $2 \%$ \\
\hline $\begin{array}{l}\text { Availability of financial resources or reduction in cost of the } \\
\text { software, etc. }\end{array}$ & $8 \%$ \\
\hline $\begin{array}{l}\text { Availability of the trained personnel and/or convenient conditions } \\
\text { of training (on the job) }\end{array}$ & $4 \%$ \\
\hline Infrastructure changes (development of the regulatory base, etc.) & $14 \%$ \\
\hline Internal readiness and motivation in the organization & $8 \%$ \\
\hline
\end{tabular}

The requirements from the customers and their readiness to work in such a format, as well as the obligation when obtaining the state order were named by the respondents as the main of such reasons. Internal readiness (of the owners / managers / designers) became the second most important factor. The availability of financial resources as the condition of the implementation of BIM technologies was noted by only $6 \%$ of the respondents.

\section{Conclusions}

Thus, 427 respondents took part in the telephone survey, which purpose was the identification of the level of introduction of BIM at the Russian enterprises of the investment-and-construction sphere. The results received during the telephone survey can be considered representative. According to the results, it is revealed that $22 \%$ of the respondents apply BIM technologies. At the same time, various level of introduction is revealed at the organizations, respectively, the result can be determined more precisely as follows: $22 \%$ of the respondents apply BIM in a varying degree (from the use of the BIM elements to the full work to the use during all the stages of work and lifecycle of the building.

Among $44 \%$ of the respondents who mentioned that they did not applied BIM technologies, about $20 \%$ form the potential of the development of the technologies, have desire and/or possibilities for the soon introduction, and only $6 \%$ firmly declare unwillingness to refuse the traditional design methods.

190 organizations of different types of activity became the participants of the online survey. $58 \%$ of the organizations from the respondents called design as the core activity. $73 \%$ of the respondents from the total selection use technologies of information modeling in their practice, $27 \%$ of the respondents do not use them. The selection was divided into 2 groups according to the answers to the question about the use of technologies of information modeling. The special block of questions was set for each group.

The survey results in the group of the organizations, which used BIM were the following:

1. The organizations, which used technologies of information modeling for their work on the projects, were differentiated according to their experience of the use of BIM (both according to the term in years and to the number of the projects implemented).

There are experienced users among the respondents who use technologies of information modeling for the project implementation (17\% of the respondents implemented 
more than 30 projects on the basis of BIM), and there are new users ( $38 \%$ of the respondents implemented no more than 5 projects on the basis of BIM).

2 . The question about the reasons, which pushed the organization to the implementation of technologies of information modeling, became one of the key questions of this research. Almost identical number of the respondents pointed out the increase in the production efficiency, the improvement of quality of the works and the search of ways of improving their competitiveness as the reasons of the introduction of BIM $(50 \%, 49 \%$ and $46 \%$, respectively). Besides, $22 \%$ of the respondents answered that the transition to BIM is connected with the requirements of the customer.

3. The initiative of the implementation of technologies of information modeling most often comes from owners of the enterprises (32\%). In $18 \%$ of cases, top management acts as initiators, in $19 \%$ of cases production divisions directly act as initiators (including, even first of all, designers). In $25 \%$ cases, the initiative comes from several parties simultaneously.

4. The main benefits of the use of technologies of information modeling, noted by vast majority of the respondents were the following:

- the improved understanding of the project by all the participants $-77 \%$;

- high quality of the project $-71 \%$;

- availability of information, fast data transmission and exchange of information $-67 \%$;

- reduction of terms of design and/or construction $-58 \%$.

5. The respondents were offered to estimate their expectations from the introduction of $\mathrm{BIM}$ and the real gained effect according to the scale from 1 to 10 , where 1 means that the real effect completely did not meet expectations and did not justify them, 5 means that the effect gained completely corresponded to those expectations which had been assigned to the introduction of BIM, 10 means that the real effect repeatedly exceeded the initial expectations. $77 \%$ of the respondents noted that the real effect of the introduction of BIM had exceeded their expectations. At the same time, $10 \%$ of the respondents said that the real effect had exceeded the expectations repeatedly. Only $7 \%$ of the respondents noted that the expectations were higher than the real effect. At the same time, the lowest marks $(1 \ldots 3$ points) were given by the organizations, which had had the experience in BIM from 1 to 3 years and has carried out no more than 10 projects with the use of BIM. The increase in the experience in BIM, perhaps, would allow those respondents to gain more considerable effect and to appreciate the use of technologies of information modeling in practice of the activity better.

The survey results in the group of the organizations, which did not use BIM were the following:

1. Answering the question about the reasons for refusal of the implementation of BIM technology, $53 \%$ of the respondents noted the absence of the competent employees able to work in BIM (some respondents noted also the lack of the opportunity to train the staff because of the lack of time or because of the need of the separation from job), $43 \%$ of the respondents noted the high implementation cost. Among this group of respondents, there were also those who consider the work of the organization effective without the use of technologies of information modeling in the organization (37).

2. $32 \%$ of the respondents of this group plan the implementation of BIM technologies. $10 \%$ of them plan the implementation within the next year, $18 \%$ within $2 \ldots 3$ years, $6 \%$ within $3 . . .5$ years. $43 \%$ of the respondents of this group do not plan the introduction of BIM in the next $3 \ldots 5$ years.

3. As for the question about the internal or external motives, which led the organization to the introduction of BIM, the main answers were:

- the requirements from the customer and his or her readiness to work in such a format as well as the obligation when obtaining the state order; 
- internal readiness (owners / managers / designers).

The availability of financial resources as the condition of the implementation of BIM technologies was noted by only $6 \%$ of the respondents.

\section{References}

1. NIBS, The National Building Information Model Standard (NBIMS) (American National Institute of Building Sciences, 2007)

2. https://www.geospatialworld.net/blogs/bim-adoption-around-the-world/ (Last accessed 04.10.2018)

3. https://www.gov.uk/government/uploads/system/uploads/attachment_data/fil e/34710/12-1327-building-information-modelling.pdf (Last accessed 03.02.2019)

4. http://www.bimplus.co.uk/people/which-country-most-bim-mature-europe/ (Last accessed 04.03.2019)

5. K. Bråthen, A. Moum, WIT Transactions on The Built Environment, 149, 157168 (2015) doi:10.2495/BIM150141

6. H. Lindblad, S. Vass, Procedia Economics and Finance, 21, 178-184 (2015) doi.org/10.1016/S2212-5671(15)00165-3

7. A. H. Memon, I. A. Rahman, I. Memon, N. Iffah Aqilah Azman, Research Journal of Applied Sciences, Engineering and Technology, 8 (5), 606-614 (2014)

8. https://www.corenet.gov.sg/media/586132/Singapore-BIM-Guide_V2.pdf. (Last accessed 16.02.2019)

9. https://www.irbnet.de/daten/iconda/CIB_DC27410.pdf (Last accessed 12.03.2019)

10. http://www.cadalyst.com/aec/to-bimfinity-andbeyond-aec-insight-column-3686 (Last accessed 17.02.2019)

11. A. M. Koucha, K. Illikainena, S. Perälä, 35th International Symposium on Automation and Robotics in Construction (ISARC, 2018)

12. V. V. Zozulya, L. I. Goncharenko, A. V. Zuikov, G. N. Semenova, Journal of Advanced Research in Law and Economics, 8(5) (2017)

13. McGraw Hill, The Business Value of BIM in North America Multi-Year Trend Analysis and User Ratings (2007-2012) in SmartMarket Report (McGraw Hill Construction, 2012)

14. https://www.smacna.org/docs/default-source/building-informationmodeling/bim-links-and-resources/measuring-the-impact-of-bim-on-complexbuildings-2015-printable.pdf?sfvrsn=2 (Last accessed 11.01.2019)

15. https://damassets.autodesk.net/content/dam/autodesk/www/solutions/pdf/Bus iness \%20Value\%20of\%20BIM\%20for\%200wners\%20SMR\%20(2014).pdf (Last accessed 10.03.2019)

16. https://www2.deloitte.com/content/dam/Deloitte/us/Documents/finance/usfas-bim-infrastructure.pdf (Last accessed 19.03.2019) 